\title{
Cold-water in situ dissolution of bamboo starch in a bioreactor: inducing forest recovery from an anthropogenic disturbance
}

\author{
M. A. Harris • C. K. Koomson
}

Received: 18 December 2013/Revised: 23 March 2014/Accepted: 8 July 2014/Published online: 31 July 2014

(C) Islamic Azad University (IAU) 2014

\begin{abstract}
Using young forest trees as the source for timber, yam sticks have in recent years produced record rates of deforestation in Jamaica and, reportedly, in Western Africa and Southeast Asia. Regeneration periods for plants producing timber yam sticks (which decompose after 2 years) are approximately 10 years compared to 3-4 years for bamboo. But when used as a yam stick, bamboo decomposes even more rapidly and hence is unsatisfactory. For treatment (a), four 7-day periods of submergence in cold, stagnant water removed carbohydrates including starch. This increased the longevity of yam sticks from 5-7 months (untreated) to a period exceeding 2 years. Treatment (b) excluded soaking, and after slowdrying, a surface coating of polyurethane was applied. This treatment marginally increased longevity. It was concluded that alcoholic alkali conditions in the stagnant cold water increased bamboo yam stick longevity by dissolving and removing the main nutrient for decomposers, namely starch. Further, lateral struts on the bamboo yam sticks substantially increased tuber yields by exposing more leaves to direct sunlight. The incentive of increased tuber yields for farmers, the improved longevity of bamboo yam sticks, and the relatively rapid growth of bamboo promises an effective tool for curbing deforestation caused by yam stick harvesting.
\end{abstract}

M. A. Harris $(\square) \cdot$ C. K. Koomson

College of Natural and Applied Sciences, Northern Caribbean

University, Mandeville, Jamaica, W.I.

e-mail: mark.harris@ncu.edu.jm

Present Address:

C. K. Koomson

Mico University College, Kingston, Jamaica, W.I.
Keywords Alcoholic alkali - Amylose $\cdot$ Cockpit Country $\cdot$ Deforestation $\cdot$ Starch dissolution

\section{Introduction}

Yam, the edible tuber of several species of the genus Dioscorea and staple food of several tropical countries, is cultivated mainly in three areas of the world: West Africa and parts of East, Central, and Southern Africa; Southeast Asia including China, Japan, and Oceania; and the Caribbean, Mexico, and parts of Central America (Otoo and Asiedu 2008). In Jamaica, the cultivation of yam entails yam stick harvesting, which removes more than 30 million saplings annually (Beckford 2000) in the western parishes, threatening the biodiversity and integrity of the Cockpit Country (Evelyn and Camirand 2003), a fragile limestone aquifer wildlife ecosystem (Evelyn and Camirand 2003) producing $40 \%$ of Jamaica's potable water (Hines 2012). Traditionally, yam farmers in Jamaica use a yam production system where heads (setts) of yams are buried in mounds ("hills") 1-2 m apart with approximately 3,000 mounds ha ${ }^{-1}$ (Barker and Beckford 2006) between 43 and 60 million vertical stakes used yearly (in Jamaica) for yam farming (Barker and Beckford 2006). This staking of yam hills significantly increases yam productivity (Otoo and Asiedu 2008). But with a current yam stick life expectancy of approximately 2 years (personal communication) and source trees having a 10-year period of regeneration (Beckford 2000), the Jamaica deforestation rate is among the highest in the world (Evelyn and Camirand 2003). As 300,000 tons of yams are exported annually to Europe and North America from Jamaica (Muzac-Tucker et al. 1993), food security and sustainable livelihoods in large sections of Jamaica depend on this crop. Additionally, it is an 
international environmental crisis causing deforestation of hundreds of thousands of acres in western Africa (Otoo and Asiedu 2008), such that an environmental and climate change mitigation strategy is required, not just in Jamaica, but probably in other regions of the humid tropics.

Based on the foregoing, any species used for yam sticks to reverse deforestation should, firstly, be capable of rapid re-growth such that its growth period is at least equivalent to yam stick longevity, and bamboo is one of the fastest growing plant species.

However, yam sticks require resistance to biological decomposition, and bamboo is poorly resistant to biological degrading agents such as brown-rot, soft-rot, white-rot fungi (Zeng et al. 2012), and beetle borers (Latif Abd et al. 1991). Considerable quantities of starch in green or dry bamboo make it more attractive to organisms such as stain fungi and borer beetles (Wahab et al. 2009). Non-structural carbohydrates (NSC) consisting of sugar alcohols such as inositol, sorbitol, and mannitol; monosaccharides, such as glucose and fructose; disaccharides such as sucrose; oligosaccharides such as raffinose and starch (Raessler et al. 2010) are the main nutrients in bamboo for the abovementioned biological agents.

With the exception of starch, the above-mentioned NSC readily dissolve in polar solvents. Such a process extends to only a limited degree of the life of bamboo when exposed to the weather. Though elevated temperatures solubilize starch (Mangalam 2005), wood thermolysis/pyrolysis can result not only in carbohydrate degradation but also in depolymerization of structural fractions such as lignin and cellulose (Mangalam 2005), thereby destroying the structural integrity of yam sticks. Though a hot water extraction helped release the carbohydrates and starch for NSC determination without affecting structural carbohydrates, Raessler et al. (2010) found that even at temperatures slightly lower than $100{ }^{\circ} \mathrm{C}$, carbohydrate values were only slightly higher with hot water extraction than with coldwater extraction. Based on these findings, heating water below $100{ }^{\circ} \mathrm{C}$ to extract starch from in situ (unmashed) bamboo would largely be a waste of energy. Very little, if any, research has been done on the effects on in situ starch in bamboos submerged in a fermenting environment. Sachdeva (2004) suggested that prolonged soaking over several weeks removed starch from bamboo, but that the water should be continuously running. Unfortunately, starch dissolution cannot be verified if the wastewater in which starch supposedly dissolved cannot be checked because it had been lost. Moreover, under such conditions of agitation and removal, there is little opportunity for chemical reactions, and starch is insoluble in pure cold water. On the other hand, the production and conservation of unique biochemical species can occur under stagnant water conditions for a particular phytochemical source. Such a reaction could solubilize starch.

The alternative to soaking is to physically exclude biological agents of decomposition using a non-toxic sealant on bamboo, and Harris et al. (1981) found that polyurethane, an impermeable polymer, is non-toxic when cured.

An additional drawback of bamboo is that yam vines do not readily attach to the smooth, glossy external surface of bamboo. This results in sagging of vines and hence reduction in tuber yields, thereby failing to provide an incentive for farmers who are asked to switch from traditional yam sticks to bamboo. However, side struts on smooth plastic yam sticks can ensure vine adherence while exposing more leaves to photosynthetic light rays. If bamboo yam sticks are constructed in such a manner, yields may be increased, thereby providing a financial incentive for farmers.

Located in Albert Town Trelawney, Jamaica, this research commenced on August 15, 2011 through to October 30, 2013.

Hypothesis

Based on the foregoing, hypothesis (a) states that prolonged soaking in stagnant water can remove not only intracellular non-starch carbohydrates but probably starch, thereby substantially decreasing biological decomposition rates of 2-year-old B. vulgaris logs used as yam sticks. Hypothesis (b) predicts that side struts on bamboo yam sticks should increase tuber yields.

\section{Materials and methods}

\section{Laboratory experiment (\#1)}

To determine the effects of water-soaking on carbohydrate removal from $B$. vulgaris, and the effects on contiguous unsoaked portions on the same bamboo log, water was used as the solvent for dissolution because of its high level of polarity. The enzyme method of starch extraction was not used due to the nondestructive requirement of this study, i.e., crushing the substrate to facilitate enzyme ingress would have destroyed the samples.

Seventy-six 2-year-old bamboos were harvested. It was necessary to choose logs of this age for the study because the nature of the deforestation requires increasing the postharvest longevity of relatively young bamboo logs. The bamboo logs were cut into 360-cm lengths and stored in shade to reduce shrinkage.

Within $12 \mathrm{~h}$ of harvest, one end of each bamboo was placed in 30-cm depth of water in a polycarbonate bucket in the upright position for 30 days. Internal septa 
(internodes) were not removed. To maintain an outward diffusion of hydrolyzed carbohydrates and for odour control, water was replaced every 3 days. At the end of this 30-day period, the samples were removed and a similar length of bamboo to the submerged part was sawn off from immediately above each water level. Samples were stored on a table in a room at ambient temperatures for 24 weeks. At the end of 24 weeks, the mass of decayed wood from each sample was determined.

Field experiment \#2: longevity

Bamboos were cut and treated according to the same dimensions as above. In addition, based on the results from experiment \#1, all internal nodes were removed with a solid iron ream of length 450 and $2.5 \mathrm{~cm}$ diameter. Holes of $2.0 \mathrm{~cm}$ diameter were drilled at approximately $90-\mathrm{cm}$ intervals along the length of each bamboo because boring holes or increasing the diffusion time results in better penetration of liquids and higher treatment loading of the sample.

\section{Polyurethane}

Having been cured in the shade for 2 weeks, harvested bamboo was coated with undiluted polyurethane applied with a paintbrush and cured for $36 \mathrm{~h}$ at $25-28{ }^{\circ} \mathrm{C}$. Harris et al. (1981) found that there is no danger to food that comes into contact with cured polyurethane. It was anticipated that the slow-curing applied to bamboo logs would help to avoid future cracking of the polyurethane.

\section{Field experiment \#3: tuber yield}

The above-mentioned holes in the bamboo also facilitated the attachment of side struts to expose more leaves to direct sunlight. Four wooden sticks of length $75 \mathrm{~cm}$ from local plants were fitted in the holes alternately in north-south/ east-west directions before bamboos were affixed in the ground as yam sticks.

Site and plot: preparations and arrangements

The experimental site is situated in east-central Jamaica in rolling karst countryside and subjected to occasional neargale force winds. In treatments one (T1 water-soaked bamboo stick), two (T2 polyurethane-coated bamboo stick), and three (T3 traditional timber stick), each yam stick supported vines from two yam hills. Observation and measuring were at 12 and 24 months, and intervening times. A completely randomized $2 \times 1$ factorial design compared the durability of two treatments (T1 vs. T2) and two tuber yields, namely side-strutted bamboo against traditional timber yam sticks (T1 or T2 vs. T3). Randomization also took into account soil variability within small distances and the sloping nature of the plot area that facilitated drainage. Samples were placed in the ground where they remained as yam sticks until they were rendered useless by decomposition. During growth, yam vines were hand-guided on the side struts of the bamboo yam sticks.

Statistics

The initial questions in this study were twofold: (1) which treatment produced a longer-lasting yam stick? (2) Do side struts increase tuber yield? For mass of decomposed material in experiment \#1, the Welch's $t$ test was used. For tuber yields, which had normal distributions, treatment means were compared using Student's $t$ test for independent unpaired samples.

Comparisons of treatments involving discrete data such as the number of decomposed bamboo yam sticks utilized the chi-square test to compare independent discrete observations (i.e., number of samples affected) of results.

\section{Results and discussion}

\section{Laboratory experiment (\#1)}

Storage was done under dry indoor conditions. The unsoaked samples produced a total of $45.25 \mathrm{~g}$ of decayed wood at an average of $5.65 \mathrm{~g}$ per batch of 8 (30-cm-long bamboo) and an standard error of means (SEM) of $0.27 \mathrm{~g}$ (Table 1). The presoaked samples produced a total of $4.46 \mathrm{~g}$ at an average of 0.558 with SEM of $.028 \mathrm{~g}$ (Table 1). By the end of the 3-month indoor storage, the presoaked samples had therefore acquired a greater-than tenfold level of resistance to decomposition compared to the unsoaked samples. Microbial decomposition of plant material varies directly with the proportion of "palatable" carbohydrate available (Harris and Rengasamy 2004). This is the case for bamboo. Biological attack on the presoaked samples weakened, compared to those without prior watersoaking (Table 1).

Yet, "dry rot" cannot occur without the presence of some moisture (Palfreyman et al. 1995). They state that biological decomposition of wood ceases below a water content of $20 \%$; hence, there is "no such thing as dry rot." Therefore, any moisture causing "dry rot" exceeded $20 \%$ water content. Bamboo therefore probably contains hygroscopic water, which, even after drying, facilitates the action of microfaunal wood degraders in the presence of sufficient NSC. As the removal of even one requirement for decomposition completely restricts the action of 
Table 1 Mass (g) of decayed bamboo produced after 24 weeks of dry storage

\begin{tabular}{lllc}
\hline & Sample properties & Presoaked for 4 weeks* & Unsoaked* \\
\hline 1 & Total & 4.46 & 45.25 \\
2 & Mean & 0.56 & 5.65 \\
3 & SEM. & 0.03 & 0.27 \\
\hline
\end{tabular}

* Each treatment batch contained eight samples. For Welch's $t$ test: null hypothesis rejected $(P<.05)$

decomposers, substantial removal of the nutrient source by the soaking treatment severely restricted the production of wood dust by decomposers.

Based on the strong odor of decaying organic matter detected after just 4 days of submergence, carbohydrates in solution were anaerobically converted to alcohols and organic acids. Due to the impermeability of dense cells that make up the tough outer skin of the bamboo, it can only be concluded that some water had moved inwards and upwards in the interior parenchymal cell layers. However, this movement was not markedly higher than the water level in the bucket because it is above this level that the above-mentioned "dry rot" occurred. Therefore, for efficient leaching of NSC from bamboo logs in water, a decision was made to remove all internal nodes for soaking in the field experiment.

\section{Field experiments (\#2, \#3)}

\section{Longevity}

Yam stick viability is determined by the response to physical stress such as that from strong winds and the mass of vegetation supported. Therefore, for bamboo, resilience varied inversely with the damage done by stem-borer insects and fungi. More than $80 \%$ of the 30-day presoaked bamboo yam sticks (T1) remained in a visually robust condition after 24 months in the field (Table 2). Though most of the T2 (polyurethane-coated) samples lasted for one season, those which did not last broke at the section of a side hole often near the base during the first season. Before the end of the second season (before 24 months), $>70 \%$ of the T2 had undergone deterioration (Fig. 1) and wind damage sufficient to render them unusable as yam sticks compared with $<20 \%$ of the T1 samples rendered unusable (Table 3).

As previously indicated, the average longevity of bamboo $\operatorname{logs}$ during exposure to the weather is less than 2 years. Therefore, by extracting carbohydrate substrates from bamboo, the water treatment of this study extended the longevity of 2-year-old bamboo sticks over that of the polyurethane-coated samples to at least 2 years. This
Table 2 Number of bamboo yam sticks affected by stem boring fauna after 24 months

\begin{tabular}{lllc}
\hline Treatment $^{\mathrm{a}}$ & $\begin{array}{l}\text { No } \\
\text { boring }\end{array}$ & $\begin{array}{l}\text { Moderate }(1-2 \text { holes } \\
\left.\mathrm{dm}^{-2}\right)\end{array}$ & $\begin{array}{l}\text { Extensive }(>2 \text { holes } \\
\left.\mathrm{dm}^{-2}\right)\end{array}$ \\
\hline $\mathrm{T} 1$ & 50 & 14 & 6 \\
$\mathrm{~T} 2$ & 6 & 12 & 58 \\
\hline
\end{tabular}

Chi-square test: degrees of freedom $=2$; null hypothesis rejected $(P<.01)$

${ }^{\mathrm{a}} \mathrm{T} 1=$ water-soaked treatment, $\mathrm{T} 2=$ polyurethane-coated treatment. Each treatment contained 70 samples. $\mathrm{T} 1=$ presoaked in water, $\mathrm{T} 2=$ polyurethane-coated

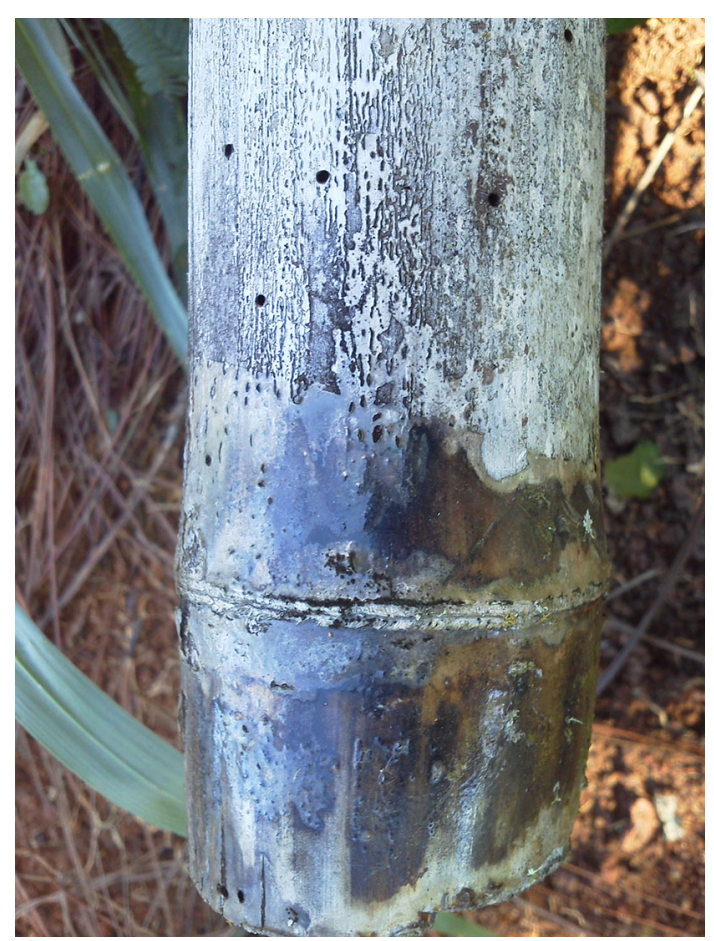

Fig. 1 Degradation resistance of subaerial polyurethane. Holes made by boring insects (upper section) were not observed where polyurethane remained intact (lower section)

was approximately twice as long as the polyurethanecoated samples, which lasted approximately for 12 months.

The intensity of attack by larvae and beetles depends on the amount of starch available (Wahab et al. 2009), and in a stack of bamboos subject to borer damage, culms that are heavily damaged are those with abundant starch (Bhat and Kallarackal 2007), being the main attractant for borers and termites in bamboo as already stated. Thus, the stagnant-soaking treatment further shows its effectiveness especially as $B$. vulgaris is among the most susceptible species of bamboo to decomposition after exposure to the ground and weather Latif Abd et al. (1991). Nevertheless, due to the insolubility of starch in water, it had been 
Table 3 Number of bamboo yam sticks damaged by winds after 24 months in the field

\begin{tabular}{llc}
\hline Treatment $^{\mathrm{a}}$ & No damage & Total damage \\
\hline T1 & 69 & 9 \\
T2 & 36 & 42 \\
\hline
\end{tabular}

Chi-square test: degrees of freedom $=1$; null hypothesis rejected $(P<.01)$

${ }^{a}$ Each treatment contained 78 samples. $\mathrm{T} 1=$ presoaked, $\mathrm{T} 2=$ polyurethane-coated

anticipated before experiment \#1 above that leaching might have been limited to hydrolyzed low-weight nonstarch carbohydrates, and that decomposition of the T1 samples would have quickly followed that of the T2 samples. Yet, even after 15 months, such an attack on the T1 by wood borers did not occur (Fig. 2). Further testing of the leachate, which had been saved from experiment \#1 and stored at $5{ }^{\circ} \mathrm{C}$ for several months, revealed that not only had sugars been dissolved from the bamboo, but starch had been released during soaking. Thus, evaporation of some of the leachate in the soak water left a substantial mass $(2 \% \mathrm{w} / \mathrm{w})$ of white, granular crystalline residue identified as starch by a blue-black reaction (Fig. 3) with Iodine Biostain C4194 gram-stain \#2 (PostApple Scientific Inc. ${ }^{\mathrm{TM}}$ ).

Moreover, because the starch was extracted from diluted water, an even higher concentration may have been removed from the bamboo. It is reasonable therefore to suggest that the soaking treatment removed a substantial proportion of parenchymal starch from the bamboo.

How did such starch dissolution occur in cold water? As stated above, sugar alcohols such as inositol, sorbitol, and mannitol, and mono- and disaccharides comprise (largely) the carbohydrates in bamboo. In such a nutrient-rich, submerged, placid environment, fermentation over several weeks occurred. The overall process of fermentation is to convert glucose sugar $\left(\mathrm{C}_{6} \mathrm{H}_{12} \mathrm{O}_{6}\right)$ to alcohol $\left(\mathrm{CH}_{3} \mathrm{CH}_{2} \mathrm{OH}\right)$ and carbon dioxide gas $\left(\mathrm{CO}_{2}\right)$. Fermentation is the process of culturing yeast under favorable thermal conditions to produce alcohol. This process is carried out at around $35-40{ }^{\circ} \mathrm{C}$ to produce ethanol from starchy materials after conversion into sugars. But, in the cold water, with sugar but no starch available, sugar was converted to alcohol, and starch may well have been conserved under such conditions as the monohydric alcohols abundant in bamboo such as inositol, sorbitol, and mannitol would have been metabolized first. Using alcoholic alkali treatments, Jane et al. (1986) reported the dissolution of starch in cold water. The absence of gelatinization in that, and in this, study proved that starch had been removed in cold water.

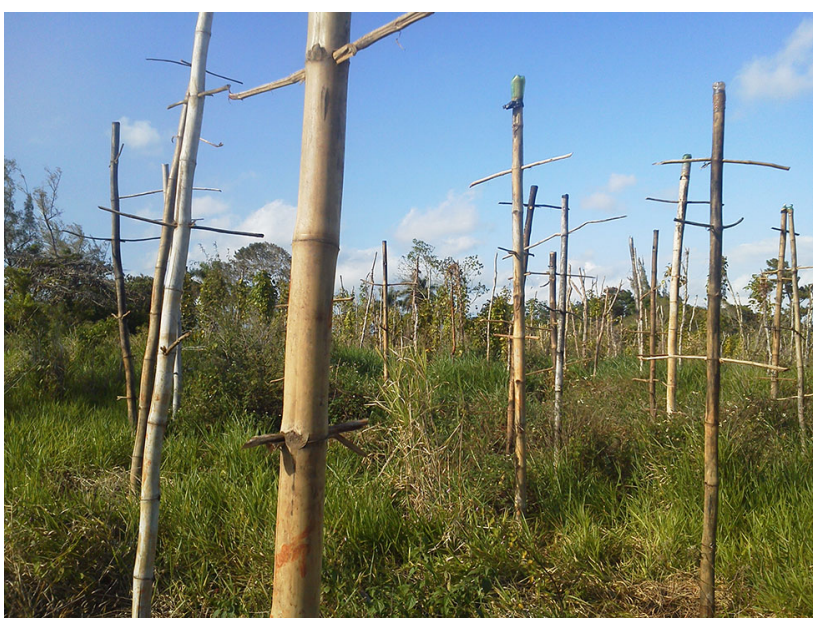

Fig. 2 Water-soaked samples: no holes made by insect borers after 2 years

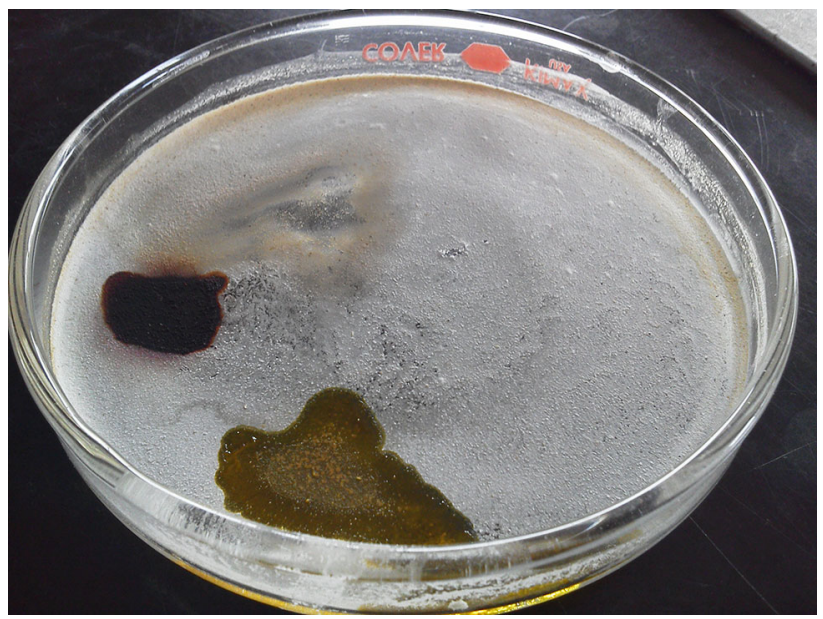

Fig. 3 Starch granules from cold-water treatment

Alkaloids are basic and occur in a limited number of plants, one of which is bamboo. As alkaloid salts are soluble in water and dilute alcohols, dissolving the alkaloids may have released free $\mathrm{OH}^{-}$ions. The reaction of such liquor with in situ parenchymal starch over several weeks could have changed the starch status from insoluble to soluble. Harris and Koomson (2010) gelatinized starch in cassava at $50{ }^{\circ} \mathrm{C}$, while Jane et al. (1986) produced a granular cold-water-soluble structure. The starch in this study also had not gelatinized because the granular crystals could be seen after samples of the fermenting liquor evaporated.

The blue-black coloration in this study shows that the starch had not cleaved, thereby indicating that enzymatic breakdown by amylase did not occur even during fermentation. The effect of fermentation on alkaloids was demonstrated by Sarangthem and Singh (2013) who 
decreased alkaloid content in fresh bamboo shoots $\left(0.98 \mathrm{mg} 100 \mathrm{~g}^{-1}\right.$ and $0.87 \mathrm{mg} 100 \mathrm{~g}^{-1}$ dry wt.) by fermenting both the samples $\left(0.63 \mathrm{mg} 100 \mathrm{~g}^{-1}\right.$ and $0.34 \mathrm{mg} 100 \mathrm{~g}^{-1}$ dry wt.). Such a "decrease" indicates that the substance was used up in reactions. This is how, in this study, cold water (originally non-alkaline) treatment could have dissolved the starch in a fermenting environment.

Bhat and Kallarackal (2007) observed that borer beetles selectively choose the inner portion of the bamboo culm wall that is rich in starch, for feeding, as compared to the outer, more fibrous part. A wavy-grained texture intrinsic to the inside surfaces of B. vulgaris would have increased the available reactive surface with the fermenting liquor. Thus, removal of the bamboo nodes in this study thereby exposing the inner surfaces to fermented cold water for 4 weeks probably enhanced starch dissolution and removal. This finding does not conflict with sources such as Sachdeva (2004), who postulated that prolonged soaking over several weeks leached starch from bamboo (though they offered no explanation for such cold-water starch removal). Based on this technique, 2-year-old bamboo forests can be harvested and maintained to achieve sustainability.

Table 4 Tuber yields $(\mathrm{kg})$ of strutted bamboo compared with traditional yam sticks

\begin{tabular}{llrc}
\hline & Properties & Traditional & $\begin{array}{c}\text { Strutted } \\
\text { bamboo }\end{array}$ \\
\hline 1 & Total & 221.8 & 271.4 \\
2 & Mean & 5.8 & 7.1 \\
3 & SEM. & 2.1 & 2.4 \\
\hline
\end{tabular}

Results for $t$ test for two independent sample means: null hypothesis rejected $(P<.05)$

\section{Polyurethane treatment}

The T2 yam sticks were effective only for the first season (12 months). This occurred despite prior slow-drying of the bamboo logs. Nevertheless, biological attack by stem borers occurred only where the polyurethane coating had lifted from the surface. Therefore, had the polyurethane coating not been applied, the insects would have done more extensive damage, and that damage would have started sooner. Polyurethane became brittle under prolonged solar radiation, but the polyurethane-coated end sections of $\mathrm{T} 2$ samples in the ground were protected from solar photolysis. No stem borers were detected on the subaerial end coated in polyurethane even after 1 year in the ground (Fig. 1).

Bhat and Kallarackal (2007) found that end-coating on harvested culms is vital to prevent borer entry, and that since borer beetles enter the culms through cut ends and other exposed points, it "will be useful" to coat all open wounds and ends of culms with some repellent substances. Polyurethane is water-repellent. Observations were that moist soil perpetually surrounded subaerial sections of polyurethane-treated bamboo even on dry days, and such sections were not punctured by biological decomposers. In addition to the escape from solar radiation, the constantly moist subaerial conditions decreased daytime temperatures, thereby reducing the amplitude of expansion/contraction compared with sections above ground, and, possibly, helping to avoid cracking of the polyurethane. T2 treatment, as carried out in this study, was successful only as a single-season remedy. A thicker layer of polyurethane might have substantially increased the longevity of the aboveground section of the bamboo, but polyurethane is costly. Nevertheless, polyurethane promises success if its aboveground photolysis can be avoided.
Fig. 4 Influence of physical morphology of yam sticks on tuber weight

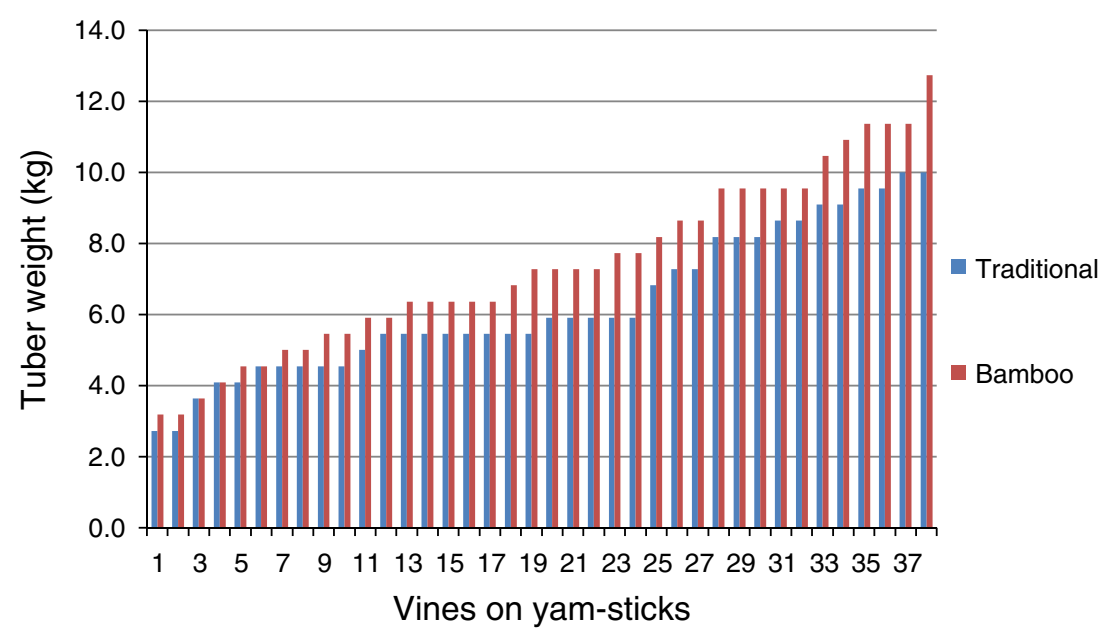




\section{Tuber yields}

Compared with traditional yam sticks, bamboo yam sticks fitted with side struts produced higher yam tuber yields, averaging $7.1 \mathrm{~kg}$ compared to $5.8 \mathrm{~kg}$ from the traditional yam sticks (Table 4, Fig. 4). These increases averaged $>18 \%$ (Table 4, Fig. 4) despite the fact that strutted bamboo yam sticks were shorter by at least $45 \mathrm{~cm}$ than traditional yam sticks. Increased yields were caused by cross-members placed through the bamboo yam sticks. This result is a repetition of the superior yam tuber yields of similarly strutted plastic yam sticks compared to traditional yam sticks in an earlier experiment (Koomson and Harris 2010). The cross-members helped to expose more leaves to direct sunlight compared to the traditional yam sticks.

\section{Conclusion}

With an aim of prolonging the life of bamboo yam sticks, two treatments were applied: (a) prolonged watersoaking and (b) surface coating with polyurethane. Exposing freshly harvested bamboo logs to four 7-day periods of stagnant water during submergence hydrolyzed carbohydrates and dissolved in situ starch. The hypothesis was supported because starch was solubilized. By reducing bamboo decomposition rate, internal and external water-soaking during submergence for 4 weeks in a fermenting medium increased the life of bamboo as yam sticks from 5-12 months to a period of up to 2 years. Further, the attachment of lateral struts on the bamboo yam sticks significantly increased tuber yields. Increased yields were correlated with (1) an increased number of leaves, and (2) exposure of more leaves to direct sunlight. These devices and yield were relative to traditional single-pole timber yam sticks, the reaping of which has, in recent years, produced largescale deforestation in and around yam-growing parishes, and, indeed, in wider regions such as Southeast Asia and Western Africa. This treatment for bamboo yam sticks is totally non-toxic, require no fossil fuels, and the carbohydrates so removed can be added to the soil for increased fertility. Due to the urgent and farreaching effects of deforestation, and the incentive of increased tuber yields from the treated bamboo, its urgent adoption by yam farmers should alleviate deforestation.

Acknowledgments The authors wish to thank Northern Caribbean University for funding this project.

\section{References}

Barker D, Beckford CL (2006) Plastic yam and plastic yam sticksperspectives on indigenous technical knowledge among Jamaican farmers. Tifdschr Econ Soc Geogr 97:533-544. doi:10.3390/ su1010081

Beckford CL (2000) Yam cultivation, the yam trade \& resource depletion in the yam growing region of central Jamaica: Integrated Problems for Planning and Management: Ph.D. Thesis, The University of the West Indies, Mona, Jamaica

Bhat KV, Kallarackal J (2007) KFRI research report 308 final technical report POST-harvest protection of bamboo from insect borers by a technique enhancing starch hydrolysis. Submitted to: National Mission on Bamboo Applications, New Delhi, 2007. Kerala Forest Research Institute, Peechi 680653 Thrissur, Kerala

Evelyn OB, Camirand R (2003) Forest cover and deforestation in Jamaica: an analysis of forest cover estimates over time. Int For Resour 5(4):354-362. doi:10.1505/IFOR.5.4.354.22659

Harris MA, Koomson CK (2010) Moisture-pressure combination treatments for cyanide reduction in grated cassava. J Food Sci 76(1):T20-T24

Harris MA, Rengasamy P (2004) Sodium affected subsoils, gypsum, and green-manure: inter-actions and implications for amelioration of toxic red mud wastes. Environ Geol 45:1118-1130

Harris JC, Rumack H, Aldrich FD (1981) Toxicity of urea formaldehyde and polyurethane foam insulation. J Am Med Assoc 245(3):87-88

Hines H (2012) Stop cutting down trees for yam-sticks. Jamaica Observer Newspaper, 29 November 2012

Jane J, Craig SAS, Seib PA, Hoseney RC (1986) Characterization of granular cold water-soluble starch. Starch/Stärke 38:258-263. doi: $10.1002 /$ star. 19860380803

Koomson CK, Harris MH (2010) Solar yam stakes increase yield. Daily Gleaner, 12 May 2010

Latif Abd M, Khoo KC, Nor Azah MA (1991) Carbohydrates in some natural stand bamboos. J Trop For Sci 4(4):310-316. ISSN $0128-1283$

Mangalam A (2005) Electroheating: a novel process for modifying wood. Master of Science Thesis. College of Graduate Studies University of Idaho

Muzac-Tucker I, Asemota HN, Ahmad MH (1993) Biochemical composition and storage of Jamaican yams (Dioscorea sp). J Sci Food Agric 62(3):219-224. doi:10.1002/jsfa.2740620303

Otoo E, Asiedu R (2008) GGE bi-plot analysis of Dioscorea rotundata cultivar "DENTE" in Ghana. Afr J Agric Res 3(2):115-125

Palfreyman JW, White NA, Buultjens TEJ, Glancy H (1995) The impact of current research on the treatment of infestations by the dry rot organism Serpula lacrymans. Intl Biodeterior Biodegrad 35:369-395. doi:10.1007/978-3-662-06398-9_6

Raessler M, Wissuwa B, Breul A, Unger W, Grimm T (2010) Chromatographic analysis of major non-structural carbohydrates in several wood species-an analytical approach for higher accuracy of data. Anal Methods 2:532-538; Royal society of chemistry 2012. doi:10.1039/B9AY00193J

Sachdeva P (2004) Bamboo for the 21st century workshop on building high-end architectural structures in bamboo 2 nd \& 3rd September 2004 Gual Pahari Campus, TERI, Gurgaon, India. http://www.bambootech.org/files/Report.pdf

Sarangthem K, Singh T (2013) Fermentation decreases the antinutritional content in bamboo shoots. Int J Curr Microbiol Appl Sci 2(11):361-369. ISSN: 2319-7706 
Wahab RA, Mohamed MT, Mustafa HA (2009) Physical characteristics and anatomical properties of cultivated bamboo (Bambusa vulgaris Schrad.) Culms. J Biol Sci 9:753-759. doi:10.3923/jbs. 2009.753.759
Zeng Y, Yang X, Yu H, Zhang X, Ma F (2012) The delignification effects of white-rot fungal pretreatment on thermal characteristics of moso bamboo. Bio-resour Technol 114:437-442. doi:10. 1016/j.biortech.2011.10.036 